\title{
Effects of Nanomaterials on the Electro-Osmotic Consolidation of Soft Soils
}

\author{
Gang $\mathrm{Li}^{1}$, Jia Liu ${ }^{2, *}$, Huanhuan $\mathrm{Li}^{1}$, Shufeng Chen ${ }^{1}$, Rui Zhang ${ }^{1}$ \\ ${ }^{1}$ Shaanxi Key Laboratory of Safety and Durability of Concrete Structures, Xijing University, Xi'an, \\ Shaanxi 710123, China; \\ ${ }^{2}$ School of Geological Engineering and Geomatics, Chang'an University, Xi'an, Shaanxi 710054, \\ China. \\ *E-mail: 15929935077@163.com
}

doi: $10.20964 / 2021.01 .53$

Received: 15 September 2020/ Accepted: 6 November 2020 / Published: 30 November 2020

Soft soil is characterized by a high water content $(w)$, high void ratio, high compressibility, poor permeability, and low shear strength $(S)$; therefore, it is not suitable as a natural foundation without proper treatment. In this study, axisymmetric electro-osmotic (EO) consolidation of soft soil was carried out, and the change laws of current $(I)$, potential $(U), w$, water discharge $(V), \mathrm{pH}, S$, and bearing capacity $(B)$ during the EO process were analyzed. The consolidation effect was enhanced by the addition of $\mathrm{SiO}_{2}$ nanoparticles or $\mathrm{Fe}_{3} \mathrm{O}_{4}$ nanosolution, and the mechanism of $\mathrm{EO}$ consolidation was determined by analyzing the macroscopic properties and microstructure of the soil. The results showed that the $I$ and $U$ in soil decreased with time $(t)$, while the $V$ increased with $t$. Near the anode, the $w$ and $\mathrm{pH}$ were low, but the $S$ and $B$ were high. The soil cracks were centered on the cathode and spread out in a cross pattern that extended to the anode. In addition, ion exchange occurred on the surface of the soil particles and inside the crystal layer, which produced a thinner electrical double layer, lower zeta potential, and lower water absorption capacity of the particles. To improve the consolidation effects, the best concentrations of nano- $\mathrm{SiO}_{2}$ and nano- $-\mathrm{Fe}_{3} \mathrm{O}_{4}$ were $3 \%$ and $2 \%$, respectively.

Keywords: Soft soil, Nanomaterials, Electro-osmosis, Consolidation, Microstructure

\section{$\underline{\text { FULL TEXT }}$}

(C) 2021 The Authors. Published by ESG (www.electrochemsci.org). This article is an open access article distributed under the terms and conditions of the Creative Commons Attribution license (http://creativecommons.org/licenses/by/4.0/). 